УДК 327.7

\title{
ВЛИЯНИЕ РАСШИРЕНИЯ ТАМОЖЕННОГО СОЮЗА НА ЭКОНОМИЧЕСКУЮ КОНКУРЕНТОСПОСОБНОСТЬ БЕЛАРУСИ И АРМЕНИИ*
}

\author{
С.Ю. СОЛОДОВНИКОВ \\ д-р экон. наук, профессор, заведующий кафедрой «Экономика и право» \\ Белорусского национального технического университета, г. Минск
}

\author{
Т.В. ИВАНОВА \\ старший преподаватель кафедры «Экономика и право» \\ Белорусского национального технического университета, г. Минск
}

\section{Аннотация}

В статье исследованы факторы, влияющие на экономическую конкурентоспособность Республики Беларусь и Республики Армении в условиях расширения Таможенного союза, а также обосновывается целесообразность вступления новых государствчленов в Таможенный союз. Формулируется вывод о том, что возможное влияние расширения Таможенного союза на экономическую конкурентоспособность Беларуси и Армении будет во многом зависеть от успешности использования ими тех конкурентных преимуществ (общих и специализированных; ресурсных, операционных и стратегических), которые объективно будут усиливаться у всех стран-участнии по мере расширения Таможенного союза, и ЕврАзЭС будет увеличиваться.

Ключевые слова: экономическая конкурентоспособность, Таможенный союз, конкурентоспособность.

\section{Abstract}

The article is devoted to the examination of the factors that influence the economic competitiveness of the Republic of Belarus and the Republic of Armenia in the context of the enlargement of Custom Union and the justification of the expediency of new member states accession to the Union. The authors come to the conclusion that possible influence of the enlargement of Custom Union on the economic competitiveness of Belarus and Armenia will depend on the successful applying of competitive advantages (general and special, resource, operational and strategic) of all member states that will grow objectively as far as the Custom Union will enlarge, and Eurasian economic community will enlarge.

Key words: economic competitiveness, the Customs Union, competitiveness.

\section{ВВЕДЕНИЕ}

В настоящее время в экономической науке все большее значение приобретает изучение сотрудничества между хозяйственными субъектами как основы повышения их конкурентоспособности. При этом акцент делается на том обстоятельстве, что смитианские взгляды на рыночную ситуацию, как поле конкурентной борьбы всех со всеми сегодня безнадежно устарели. Так, например, «теория «соконкуренции» профессора Гарвардского университета А.М. Бранденбургера и профессора экономики Йельской

\footnotetext{
* Статья подготовлена в рамках реализации договора с БРФФИ на выполнение научноисследовательской работы по теме «Расширение Таможенного союза как фактор повышения экономической конкурентоспособности стран-участниц: на примере Беларуси и Армении» № Г14АРМ-007 от 23.05.2014 г.
} 
школы менеджмента Б.Дж. Нейлбаффа, подчеркивает необходимость как конкуренции, так и сотрудничества в зависимости от конкретной ситуации. В то время как модель М. Портера «Пять сил конкуренции» применяется в основном для анализа конкуренции между различными типами игроков в отрасли, А. Бранденбургер и Б. Нейлбафф вводят в нее шестую силу, называемую сателлитами» [1, с. 32]. В данном случае речь идет о таких формах экономического сотрудничества, когда последнее осуществляется между партнерами, существенно отличающимися между собой своей экономической мощью. Тем не менее, такая форма кооперирования оказывает свое положительное влияние на конкурентоспособность ее участников как на уровнях коммерческих организаций, так и на межгосударственном уровне. Именно эту особенность усиления экономической конкурентоспособности всех стран-участниц Таможенного союза, по мере его расширения, необходимо учитывать при выработке стратегических направлений развития этого союза и ЕврАзЭС. Разумеется, что расширение Таможенного союза будет вести к росту экономической конкурентоспособности стран-участниц только при условии положительного синергетического влияния на этот процессе факторов, его обуславливающих за счет, во-первых, снижения социальных, политических и экономических рисков (внешних шоков), возникающих в результате усиления глобальной политэкономической нестабильности, расширения феномена глобальных финансов и растущего применения на международной арене информационного оружия как способа разрушения экономик стран-конкурентов, и, во-вторых, повышающих технологический, социальный, экономический, институциональный, культурный потенциалы и увеличивающих внутреннее потребление, которые выступают объективной базой роста конкурентоспособности стран-участниц.

\section{РЕЗУЛЬТАТЫ И ИХ ОБСУЖДЕНИЕ}

Как справедливо отмечает О.Н. Беленов: «Общие факторы конкурентоспособности - это факторы, действующие в широком спектре отраслей и влияющие на конкурентоспособность страны. К ним могут быть отнесены развитая инфраструктура, высокий уровень человеческого потенциала, положительная динамика рождаемости, благоприятный климат. Специализированные факторы конкурентоспособности - это факторы, которые либо могут быть использованы в одной конкретной отрасли, либо в определенный момент» [1, с. 34]. К специализированным факторам производства принято относить наличие научно-исследовательских центров, высокую долю высококвалифицированных индустриальных рабочих (не менее 40 \% от общего количества индустриальных рабочих), высокий уровень остепененности научных сотрудников, наличие высококвалифицированных инженеров и т.д. Именно «синергетическое действие общих и специализированных конкурентных преимуществ способствует созданию долгосрочных конкурентных преимуществ, которые трудно «скопировать» конкурентам» [1, с. 34]. Конкурентоспособность национальной экономики также обеспечиваются дополнительным синергетическим эффектом от таких конкурентных преимуществ как, во-первых, ресурсные, т.е. «нацеленность субъектов конкурентоспособности различными видами ресурсов, которых нет у конкурентов, и которые при определенных условиях могут способствовать высокой конкурентоспособности экономических субъектов» [1, с. 34], во-вторых, операционные, т.е. «совокупность организационных, экономических, научно-технологических факторов, позволяющих субъекту конкурентоспособности добиваться высокой эффективности использования имеющихся в его распоряжении ресурсов и на этой основе снижать издержки и цены, повышая конкурентоспособность своих товаров» [1, с. 34] и, в-третьих, стратегические, т.е. «совокупность стратегических решений и принятых программ развития фирмы, предприятия, экономики страны, позволяющих оптимально сочетать их ресурсную базу, истори- 
ко-культурные и экономико-организационные особенности для формирования уникального пути развития, что делает субъект конкурентоспособности недосягаемым для глобальных конкурентов» [1, с. 34].

Возможность использовать все эти конкурентные преимущества (общие и специализированные; ресурсные, операционные и стратегические) объективно будет усиливаться у всех стран-участниц по мере расширения Таможенного союза и ЕврАзЭС. Вместе с тем для того чтобы эти возможности были реализованы в повышение конкурентоспособности конкретных стран участниц (например Беларуси и Армении), необходимо наличие соответствующе экономической стратегии на государственном уровне.

Поскольку конкурентоспособность стран-участниц, которые в свою очередь можно рассматривать как регионы ЕврАзЭС, может быть рассмотрена как система, состоящая из таких институциональных составляющих, как: «конкурентный потенциал региона; факторы и условия формирования конкурентной среды; эффективность использования ресурсов; конкурентные преимущества; конкурентные стратегии хозяйствующих субъектов; государственные и рыночные механизмы управления экономическим потенциалом региона для более полного удовлетворения потребностей человека» [2, с. 46], то правомерен вывод об усилении значения институционально-правовой компоненты в процессе расширения Таможенного союза.

18 ноября 2011 года главами трех государств - Российской Федерации, Республики Беларусь и Республики Казахстан - была принята «Декларация о евразийской экономической интеграции». Как следует из Декларации, к 2015 году должна быть завершена кодификация нормативно-правовой базы Таможенного союза и Единого экономического пространства. Это означает систематизацию законодательства, качественную переработку действующих норм, устранение несогласованностей, восполнение пробелов и отмену устаревших норм. Кодификация не предусматривает пересмотр ранее достигнутых договоренностей, наоборот, они приобретают систематизированный вид, приводятся к общему знаменателю [3].

Согласно логике развития интеграции, основные направления перехода от Единого экономического пространства к Евразийскому экономическому союзу включают передачу Евразийской экономической комиссии полномочий по инициированию и принятию решений, а также создание союзных институтов регулирования экономики в рамках переданных на наднациональный уровень функций с формированием соответствующих механизмов контроля, обеспечением прозрачности процессов управления и ответственности за результаты. С учетом опыта строительства Европейского союза для этого может быть предложена следующая последовательность действий, наряду с уже принятыми и осуществляемыми планами по созданию Единого экономического пространства, развитию Таможенного союза, формированию единой системы технического регулирования.

Во-первых, должна быть завершена работа по приведению национальных законодательств государств-членов в полное соответствие с договорно-правовой базой Единого экономического пространства.

Во-вторых, необходимо завершить устранение остающихся барьеров во взаимной торговле по согласованным планам.

В-третьих, критически необходимо создание интегрированной информационной системы внешней и взаимной торговли, обеспечивающей применение современных информационных технологий при осуществлении всех переданных в ведение Таможенного союза видов государственного контроля в режиме «единого окна», формирование плана мероприятий по ее разработке и реализации.

В-четвертых, крайне актуальным является совершенствование механизма и правового обеспечения статистики взаимной торговли. В целях повышения уровня 
полноты, достоверности и качества разрабатываемых и публикуемых данных статистики взаимной торговли стран-членов Таможенного союза необходимо организовать функциональное взаимодействие национальных и наднациональных статистических органов, создать условия для полноценного участия последних в мировой системе статистических организаций путем углубления статистических баз данных, применения современных информационных технологий, повышения квалификации кадров и научной обоснованности принимаемых решений. Следует унифицировать статистическую форму декларирования товаров, поставляемых в рамках взаимной торговли.

Особую сложность представляет решение проблемы повышения ответственности декларантов за достоверность сообщаемой информации по операциям взаимной торговли. В рамках действующего в России законодательства о статистике таковая фактически отсутствует. Выходом из этого положения может стать привлечение налоговой службы к формированию агрегированных данных о товарных потоках в физических и стоимостных показателях.

В-пятых, необходимо ликвидировать пробел в договорно-правовой базе Таможенного союза в связи с нерешенностью вопроса о введении в действие Соглашения о едином порядке экспортного контроля государств - членов Таможенного союза. Сохранение экспортного контроля во взаимной торговле уже не может быть обеспечено в силу отсутствия таможенного контроля. Без унификации национальных норм экспортного контроля затруднено их правоприменение и на внешней границе Таможенного союза.

В-шестых, Таможенный союз не может считаться завершенным без унификации торговых режимов. Завершение формирования зоны свободной торговли Таможенного союза с заинтересованными государствами СНГ, а также с Сербией и Черногорией очерчивает контур «второго круга» евразийской интеграции. В дополнение к нему необходимо определение перечня государств, с которыми целесообразно установление преференциальных торговых режимов.

В-седьмых, для обеспечения эффективного правоприменения законодательства Таможенного союза и Единого экономического пространства необходима гармонизация систем административной и уголовной ответственности за совершение правонарушений в сферах регулирования, переданных на наднациональный уровень.

В-восьмых, целесообразна унификация норм национальных законодательств в сфере государственной службы, определяющих статус чиновников, работающих в наднациональных структурах.

В-девятых, для завершения формирования единой таможенной территории целесообразно создание единой системы лицензирования внешнеторговых операций Таможенного союза.

После решения перечисленных выше вопросов возможен переход к формированию Евразийского экономического союза. Особенно важно введение в действие интегрированной информационной системы внешней и взаимной торговли, обеспечивающей прозрачность всех функций государственного управления Единой таможенной территорией, включая функционирование наднационального органа, а также обеспечение надежной статистики взаимной и внешней торговли. После этого станет возможным внесение в договорно-правовую базу Единого экономического пространства изменений, предоставляющих наднациональному органу права самостоятельной разработки и инициирования решений в рамках переданных Таможенному союзу и Единому экономическому пространству полномочий.

Для направления процесса евразийской интеграции на решение целей экономического развития необходима разработка и принятие Единой стратегии торговоэкономической политики Единого экономического пространства, концепций единой 
промышленной и сельскохозяйственной политики, а также планов их реализации. Это предполагает гармонизацию национальных и союзных политик развития: промышленной, сельскохозяйственной, научно-технической, энергетической, транспортной и др. В дальнейшем необходимо создание системы стратегического планирования развития Евразийского экономического союза, включающей долгосрочные прогнозы, среднесрочные концепции и стратегии торговой, промышленной, сельскохозяйственной, научно-технической политики, основные направления социальноэкономической, денежно-кредитной и налоговой политики, а также межгосударственные программы и планы мероприятий по их реализации. Следует как можно скорее разработать и утвердить стратегический план развития Евразийского экономического союза и программы его реализации на десятилетие вперед.

В дополнение к планам формирования Единого экономического пространства для эффективного функционирования единого финансового рынка необходимо установление единых требований к деятельности кредитных рейтинговых агентств. В дальнейшем для углубления интеграции необходима гармонизация национальных налоговых систем, формирование единой платежной системы и общего финансового регулятора. Целесообразно также придание рублю статуса резервной валюты Евразийского экономического союза.

Для обеспечения нормальной работы рынка труда необходима унификация квалификационных требований и обеспечение взаимного признания документов об образовании и квалификации, выдаваемых в соответствии с установленным порядком.

После принятия решений о присоединении Кыргызстана и Таджикистана к Таможенному союзу и Единому экономическому пространству, определения перспектив участия других государств, а также кодификации договорно-правовой базы евразийской интеграции возможно подписание международных договоров в сфере деятельности Евразийского экономического союза, предусматривающего правопреемство институтов Таможенного союза, Единого экономического пространства, ЕврАзЭС, а также трансформацию институтов ЕврАзЭС и Евразийской экономической комиссии в институты Евразийского экономического союза. На этом этапе целесообразно формирование советов министров и руководителей государственных ведомств государств-членов соответствующего профиля в качестве вспомогательных и совещательных органов Евразийской экономической комиссии, а также унификация паспортно-визового режима и отмена паспортного пограничного контроля на межгосударственных границах государств-членов Евразийского экономического союза [3; 4].

Увеличение числа участников интеграционного объединения создает возможности для расширения внутреннего рынка Единого экономического пространства, интеграции в мировое хозяйство и повышения интереса со стороны зарубежных инвесторов.

Расширение Таможенного союза отвечает интересам всех государств-участников. По заявлению министра иностранных дел Республики Беларусь В.В. Макея, «Республика Беларусь неоднократно подчеркивала, что двери интеграционного объединения открыты для наших партнеров, разделяющих его цели и готовых присоединиться к договорно-правовой базе Таможенного союза/Единого экономического пространства. Новые страны - это новые возможности. Их приход будет означать расширение рынка, новый уровень для сотрудничества и взаимовыгодной кооперации» [5].

В экономической сфере для Республики Беларусь перспективным направлением сотрудничества государств-членов Таможенного союза является реализация конкретных совместных программ и проектов, нацеленных, в первую очередь, на 
модернизацию и переход к инновационному пути развития экономик государствчленов. В приоритетных сферах - энергетика и энергоэффективность, информационные технологии, космос и медицина, развитие регионального сотрудничества. Задача Беларуси - выйти на оптимальные формы промышленной и научно-технической интеграции, задействовать весь потенциал для производства высокотехнологичной и конкурентоспособной продукции.

Белорусская сторона твердо отстаивает свои подходы к условиям интеграции, основанные на необходимости обеспечения конкурентоспособности и успешного функционирования наших предприятий в средне- и долгосрочной перспективе. Особый расчет при расширении Таможенного союза делается на обеспечение выхода совместной продукции на рынки третьих стран.

При расширении Таможенного союза за счет новых государств-членов, таких как Таджикистан, Тунис, Турция, Сирия, отрасли, где взаимопроникновение возрастает, могут стать основой для создания совместных предприятий и промышленной кооперации. В Казахстане уже создан ряд совместных предприятий по производству белорусской техники (тракторы, комбайны, карьерная техника, двигатели, лифты и др.). Аналогичные предприятия успешно работают и в России.

В настоящее время ведется работа по пяти интеграционным промышленным проектам: автомобильный холдинг «РОСБЕЛАВТО» (ОАО «МАЗ» - ОАО «КАМАЗ»); ОАО «Интеграл» и ОАО «Российская электроника» ГК «Ростехнологии»; ОАО «МЗКТ» и ГК «Ростехнологии»; ОАО «Пеленг» и Федеральное космическое агентство «Роскосмос»; ОАО «Гродно-Азот» и ОАО «МХК «ЕвроХим» либо ООО «Газпром Инвестпроект» [5].

В сентябре 2013 года Президент Армении С. Саргсян заявил о присоединении Республики к Таможенному союзу, в органы управления интеграцией подана соответствующая заявка.

2 января 2015 года Армения официально вступила в Евразийский экономический союз. Членство страны в Евразийском экономическом союзе пока будет ограниченным: у нее будет ограниченное представительство в Евразийской экономической комиссии, а ряд таможенных ставок и пошлин она введет позднее. Долю Армении в объеме таможенных пошлин, которые будут получать от ввоза товаров на территорию Евразийского экономического союза, агентство ТАСС оценивает в 1,13 \%. При этом в сфере услуг Армения присоединится к договоренностям членов союза на общих основаниях, а в сфере торговли товарами будет предусмотрен постепенный переход к единому тарифу Евразийского экономического союза. До 2018 года страна также будет применять нулевые таможенные ставки на бензин. К ставкам единого таможенного тарифа страна перейдет в 2020 году [6].

В настоящее время интенсивность торговли России и других государств-членов Таможенного союза с Арменией является весьма высокой. В 2012 году объем экспорта России в Армению составил 915,5 млн. долларов. Основными товарами российского экспорта в Армению стали минеральные продукты (доля - 52,1 \%); продовольственные товары и сельхозсырье (19,0 \%); машины, оборудование и транспортные средства $(14,2 \%)$; металлы и изделия из них $(7,1 \%)$; продукция химической промышленности и каучук $(4,3 \%)[6]$.

В структуре импорта государств-членов Таможенного союза из Армении преобладают продовольственные товары и сельхозсырье $(73,9 \%)$; машины, оборудование и транспортные средства $(10,9 \%)$; драгоценные камни, драгметаллы и изделия из них (9,1%); текстиль, текстильные изделия и обувь (1,1\%) [6].

Интеграционные эффекты для Армении будут в основном связаны с возможностями относительного увеличения экспорта в страны Единого экономического пространства, которые могут обеспечить прирост ВВП около 0,3-0,4 \%. Возможности 
прироста ВВП за счет внутриотраслевой кооперации или снижения цен на энергоносители являются незначительными. Таким образом, возможный экономический эффект от присоединения Республики Армении к Таможенному союзу и Единому экономическому пространству без дополнительных усилий с российской стороны в виде, к примеру, инвестиционных проектов, является значительным.

Вместе с тем, учитывая стратегическую значимость Закавказья для Таможенного союза и Евразийского экономического союза, следует комплексно решать задачу интеграции структур Единого экономического пространства с Арменией, развивая взаимоотношения с Грузией, Азербайджаном и Турцией. При этом целесообразно использовать потенциал Республики Казахстан как тюркоязычной страны.

Транзитные и таможенные правила Таможенного союза при их распространении на Армению позволяют упростить процедуру пропуска грузов по этим коридорам. А технологической «подпоркой» здесь является проект прямого железнодорожного сообщения «Армения - Иран». Осуществление этого проекта в рамках Таможенного союза проложит для экспортных товаров из стран Таможенного союза наиболее короткий сухопутный маршрут к портам Персидского залива. Свыше 60 \% объема грузоперевозок между Арменией и странами Таможенного союза, в том числе 100 \% объема поставок газа из Российской Федерации, идут через Грузию. Для решения вопросов по транзиту может использоваться практика транзитных соглашений в других регионах Таможенного союза - например, между Калининградом, Литвой, Беларусью и остальной территорией России.

Кроме того, распространение на Армению правил Таможенного союза в сфере капиталовложений ускорит приток в ее экономику инвестиций из других стран Таможенного союза, в том числе в энергетику. Президент Российской Федерации выделил в этой сфере такие крупные проекты с российским участием, как продление срока действия Армянской АЭС до 2026 г.; участие «Газпрома» в строительстве газопровода «Иран - Армения»; обновление Севана-Разданского каскада ГЭС с помощью «Интер РАО ЕЭС». Эти проекты позволят увеличить экспорт электроэнергии из Армении, в чем заинтересованы многие соседние страны.

Вступление Армении в Таможенный союз обусловлено также динамикой ее связей со странами союза, особенно с Российской Федерацией. Так, Россия - ведущий торговый партнер Армении. А объем прямых инвестиций Российской Федерации в этой стране уже превысил 2,4 млрд долл. - это почти 45 \% прямых зарубежных инвестиций в экономику Армении. И более $25 \%$ совместных предприятий с иностранным участием в этой стране приходится на российско-армянские. Подтверждением заинтересованности Российской Федерации в участии Армении в Таможенном союзе является и тот факт, что Москва в конце августа согласилась частично субсидировать цены на российский газ для этой страны. До $90 \%$ газового спроса Армении - это поставки из России [7].

Существуют и проблемные факторы участия Армении в Таможенном союзе. Как считает вице-президент Торгово-промышленной палаты Российской Федерации Георгий Петров, решение Армении вступить в Таможенной союз обусловлено тем, что страны Таможенного союза, прежде всего Россия, являются основными экономическими партнерами Армении. Крупнейшим инвестором в ее экономику остается опять же Россия. Членство в Таможенном союзе, как подчеркивает Г. Петров, предполагает целый ряд изменений в экономической, в том числе в таможенной нормативно-правовой базе вступающей страны. Поэтому следует ожидать соответствующих решений правительства и парламента Армении, нацеленных на то, чтобы на эту страну распространялась нормативно-правовая база Таможенного союза [7]. 


\section{ВЫВОДЫ}

Таким образом, возможное влияние расширения Таможенного союза на экономическую конкурентоспособность Беларуси и Армении будет во многом зависеть от успешности использования ими тех конкурентных преимуществ (общих и специализированных; ресурсных, операционных и стратегических), которые объективно будут усиливаться у всех стран-участниц по мере расширения Таможенного союза, а ЕврАзЭС будет увеличиваться. Вместе с тем, для того чтобы эти возможности были реализованы в повышение конкурентоспособности конкретных стран-участниц (например Беларуси и Армении), необходимо наличие соответствующе экономической стратегии на государственном уровне. При этом усиливается значение институционально-правовой компоненты в процессе расширения Таможенного союза.

\section{ЛИТЕРАТУРА}

1. Беленов, О.Н. Конкурентоспособность стран и регионов: учебное пособие / О.Н. Беленов, А.Д. Анучин. - М.: КНОРУС, 2011. - 144 с.

2. Дохолян, С.В. Предпосылки развития региональной конкурентоспособности / С.В. Дохолян, В.З. Петросянц // Региональные проблемы преобразования экономики, 2007. - №1- С.46-50.

3. Беларусь и международные организации // Официальный сайт Министерства иностранных дел Республики Беларусь [Электронный ресурс] - Режим доступа: http://mfa.gov.by/mulateral/organization/. - Дата доступа: 27.09.2015.

4. Интеграция и макроэкономика // Официальный сайт Евразийской экономической комиссии. [Электронный ресурс]. - Режим доступа: http://eec.eaeunion.org/ru/act/integr_i_makroec. - Дата доступа: 27.09.2015.

5. Расширение Таможенного союза отвечает интересам всех государств-участников // Газета «Звязда» «Союз - Евразия». - 1 апреля 2014 г. [Электронный pecypc]. - Режим доступа: http://zviazda.by/category/gazeta. - Дата доступа: 27.09.2015.

6. Армения и Таможенный союз: оценка экономического эффекта интеграции ЦИИ ЕАБР, 2013. - 48 с.

7. Балиев, А. Через две границы / А. Балиев // Российская Бизнес-газета. № 913 (35) [Электронный ресурс] - Режим доступа : http:// www.rg.ru/2013/09/10/ts.html. Дата доступа: 27.09.2015.

Статья поступила в редакцию 25 ноября 2015 года. 